\title{
O TORNAR-SE PROFESSOR(A) NO CURRÍCULO DE CIÊNCIAS: tensionando as teses culturais da BNCC e da BNC-Formação
}

\author{
Catarina de Cássia Moreira \\ Universidade Federal do Rio de Janeiro - UFRJ, Brasil \\ Beatriz Pereira \\ Universidade Federal de Santa Catarina - UFSC, Brasil \\ Marcia Serra Ferreira \\ Universidade Federal do Rio de Janeiro - UFRJ, Brasil
}

\begin{abstract}
Resumo
Neste trabalho procuramos identificar como os textos das políticas curriculares brasileiras (BNCFormação e BNCC) participam da constituição de teses culturais sobre a subjetividade docente, com efeitos no ensino das disciplinas escolares em ciências. No diálogo com autores da História do Currículo, em especial Thomas Popkewitz, identificamos duas teses culturais sobre o(a) professor(a) que, articuladas, produzem a formação de professoras(es) nessas políticas: i) professoras(es) como implementadores da BNCC da Educação Básica; e ii) professoras(es) responsáveis pela melhoria dos índices do país em avaliações de larga escala. Nesse contexto, a formação das(os) professoras(es) que atuam nas disciplinas escolares em ciências vai sendo produzida de modo a colocar os conhecimentos, procedimentos e métodos das ciências de referência - em especial as Ciências Biológicas, a Física e a Química - e a utilidade social da disciplina a serviço dessas teses culturais. Tornar visível as formas por meio das quais sujeitos(as)-professores(as) habitam a norma é uma maneira de resistir, de encontrar brechas para desterritorializar os processos educativos, podendo assim encontrar outras formas de fazer educação que questionam e subvertem a normatividade.
\end{abstract}

Palavras-chave: Currículo; Formação de professoras(es); Ensino de ciências; História do currículo; Teses culturais.

\begin{abstract}
In this paper, we aim to identify how the texts of Brazilian curriculum policies (BNC-Formação and BNCC) participate in the constitution of cultural theses about teacher subjectivity, which bring into play effects on the teaching of school subjects related to science education. In a dialogue with authors from the Curriculum History field, especially Thomas Popkewitz, we identified two cultural theses about the teacher that, when articulated, produce teacher education in these policies: i) teachers as enactors of the BNCC in Basic Education; and ii) teachers as responsible for improving the country's scores in large-scale assessments. In this context, the training for science education teachers is produced in such a way as to place the knowledge, procedures and methods of the school subjects' academic field of reference - in particular Biological Sciences, Physics and Chemistry - as well as their perceived social utility at the service of those cultural theses. To make the ways in which subject-teachers inhabit the norm visible is a way of resisting, of finding breaches to deterritorialize educational processes, thus being able to find other ways of doing education that interrogate and subvert normativity.
\end{abstract}

Keywords: Curriculum; Teacher training; Science education; Curriculum history; Cultural theses.

ISSN 1645-1384 (online) www.curriculosemfronteiras.org 


\section{Introdução}

Neste artigo, buscamos identificar como a Base Nacional Comum Curricular para a Educação Básica (BNCC) (Brasil, 2017) e a Base Nacional Comum para Formação Inicial de Professores da Educação Básica (BNC-Formação) (Brasil, 2019), participam da produção de teses culturais sobre a subjetividade docente, com efeitos na formação de professores(as) para a atuação nas disciplinas escolares em ciências ${ }^{1}$. Ainda que o foco da investigação não esteja nos conhecimentos a serem ensinados na educação básica, optamos por incluir na análise as discussões da BNCC (Brasil, 2017) a fim de tensionar os modos como nos tornamos professoras(es). Afinal, ainda que o documento indique suas limitações frente ao quadro de desigualdades educacionais no país, ele se coloca como "essencial para que a mudança tenha início porque, além dos currículos, influenciará a formação inicial e continuada dos educadores, a produção de materiais didáticos, as matrizes de avaliação e os exames nacionais" (Brasil, 2017, p. 05). Além disso, a BNCC é enunciada como parte integrante de uma política nacional para educação básica que alinha outras políticas e ações, em âmbito federal, estadual e municipal, voltadas para a avaliação, a infraestrutura e a formação de professoras(es) (Brasil, 2017).

Partimos de investigações gestadas no âmbito do Grupo de Estudos em História do Currículo (GEHC) da Universidade Federal do Rio de Janeiro (UFRJ) que, em diálogo com Michel Foucault e Thomas Popkewitz, vem construindo uma abordagem discursiva para a História do Currículo como História do Presente, em articulação com as Políticas de Currículo (Ferreira, 2014; 2015; Ferreira; Santos, 2017). Tal abordagem tem nos permitido compreender que é no jogo da linguagem que significamos as coisas do mundo, uma vez que, de acordo com ela:

Nada pode ser definido e significado fora desse jogo, não sendo possível, nessa perspectiva, pensar em uma materialidade que defina o sentido último das coisas. Assim, embora possamos admitir a existência dessa materialidade, é o ato de (re)nomear algo que constrói a diferença, que significa admitir que o real é discursivamente construído (Ferreira; Santos, 2017, p. 60).

É com ela, portanto, que compreendemos a BNCC e a BNC-Formação como superfícies textuais que participam da produção de discursos reformistas da educação no Brasil. No diálogo com Jefferson Mainardes, Márcia dos Santos Ferreira e César Tello (2011, p. 157), reconhecemos que os textos das políticas "são produtos de múltiplas influências e agendas, e a sua formação envolve intenções e negociação dentro do Estado e dentro do processo de formulação", e que nem todas agendas e influências são reconhecidas como "legítimas" de compor os textos políticos. Ainda assim, no diálogo com Michel Foucault e Thomas Popkewitz, assumimos que mesmo essas agendas e influências supostamente menos "legítimas" participam de disputas que produzem e hegemonizam significados sobre aquilo que somos e sabemos (Ferreira, 2014). É nesse contexto que a reforma como discurso não deve ser entendida "como portadora de informações sobre as práticas que induzirão à 
transformação social que se quer, mas como discurso que se articula com outros para produzir a significação em torno do que seria a mudança" (Ferreira; Santos, 2017, p. 64).

Entendemos que no Brasil, a formação de professores(as) para a atuação nas disciplinas escolares em ciências tem sido tensionada por políticas curriculares que, desde os anos de 1990, investem em teses culturais sobre como os sujeitos da educação (professores(as) e estudantes) são e/ou devem ser. Os textos das políticas aqui investigadas (Brasil, 2017; 2019) participam de um sistema de pensamento que nos possibilita pensar o ensino e a formação de professores de determinados modos e não de outros, constituindo "regras e padrões que ordenam práticas curriculares e de ensino" (Popkewitz, 2020, p. 49). Segundo Thomas Popkewitz (2020), essas regras e padrões são historicamente produzidas e funcionam como teses culturais sobre como os estudantes devem ser, viver e agir no mundo, com vistas à produção de cidadãos cosmopolitas autossuficientes, capazes de tomar as melhores decisões por meio do uso da razão. No diálogo com esse autor, percebemos que essas teses culturais funcionam, igualmente, na produção de professoras(es) capazes de atuar na constituição desses estudantes/cidadãos.

Ao questionar o modo como vimos cristalizando a ideia de uma identidade docente pautada em representações essencializadas e fixas, assumimos que as políticas curriculares produzem qualificações e categorizações acerca dos sujeitos, que por sua vez, estão em constante processo de sujeição. Para Judith Butler (2020, p. 18), "os domínios da 'representação' política e linguística estabeleceram a priori o critério segundo o qual os próprios sujeitos são formados, com o resultado de a representação só se estender ao que pode ser reconhecido como sujeito". Tal movimento nos ajuda a pensar como os textos curriculares aqui investigados - a BNCC e a BNC-Formação - pretendem discursivamente montar ideias sobre os sujeitos jurídicos da política principalmente por meio das práticas de exclusão daqueles que não parecem estar estabelecidos e inscritos na estrutura jurídica da política.

Nesse quadro teórico, o movimento não seria o de tentar nos desfazer do sujeito da representação, mas sim, como nos convida Judith Butler (2020, p. 24, grifo nosso), o de "formular, no interior dessa estrutura constituída, uma crítica às categorias de identidade que as estruturas jurídicas contemporâneas engendram, naturalizam e imobilizam”. Tal crítica, de acordo com a autora, não tem por objetivo "avaliar se os seus objetos - condições sociais, práticas, formas de conhecimento, poder e discurso - são bons ou ruins, altamente valorizados ou menosprezados, mas sim pôr em relevo a própria estrutura de avaliação" (Butler, 2013, p. 162). A crítica é, portanto, uma prática que requer determinada parcela de paciência, pois ela pode vir a depender dos objetos que são colocados na perspectiva de nossas lentes.

É em meio ao exercício dessa crítica que percebemos o tornar-se professor(a) como sujeição, um movimento que é

[...] tanto o processo de se tornar subordinado pelo poder quanto o processo de se tornar um sujeito. Seja pela interpelação, no sentido de Althusser, seja pela produtividade discursiva, no sentido de Foucault, o sujeito é iniciado através de uma submissão primária ao poder" (Butler, 2019, p. 10). 
Isso significa, paradoxalmente, que estamos nos referindo a um(a) professor(a) que ainda não existe, um sujeito que contingencialmente vem sendo feito em camadas, também pelos discursos das políticas educacionais. Afinal, nesse quadro teórico o indivíduo torna-se sujeito por meio da linguagem. Não há, portanto, um sujeito fazedor, mas sim aquele produzido na (e pela) linguagem. Ele é, então, "a ocasião linguística para o indivíduo atingir e reproduzir a inteligibilidade, a condição linguística de sua existência e ação" (Butler, 2019, p. 19). No diálogo com Michel Foucault (2008, p. 61), entendemos também que "o discurso, assim concebido, não é a manifestação, majestosamente desenvolvida, de um sujeito que pensa, que conhece, e que o diz: é, ao contrário, um conjunto em que podem ser determinadas a dispersão do sujeito e sua descontinuidade em relação a si mesmo".

Focalizando a produção de teses culturais sobre a subjetividade docente, com efeitos na formação de professores(as) para atuação nas disciplinas escolares em ciências, optamos por analisar na íntegra o Parecer CNE/CP no 22 aprovado em 07 de novembro de 2019 (Brasil, 2019). Este documento possui três partes, sendo a primeira um relatório de trabalho da comissão que construiu o documento, que procura justificar a relevância da implementação da BNC-Formação no Brasil, principalmente, a partir de referenciais internacionais e de resultados do país em avaliações de larga escala. Além disso, apresentam-se no relatório princípios desta política de formação docente, sua organização curricular e as competências almejadas para estes profissionais. A segunda parte do documento é um projeto de Resolução ${ }^{2}$, que visa a definir diretrizes curriculares nacionais para a formação inicial de professores(as) e instituir a BNC-Formação. Por fim, junto ao projeto de Resolução há um anexo intitulado Base Nacional Comum para a Formação Inicial de Professores da Educação Básica (BNC-Formação), que apresenta as competências gerais docentes e as competências específicas.

Além disso, como já explicitado, incluímos na pesquisa a BNCC (Brasil, 2017), optando por focar a análise em três seções do documento. Nas duas primeiras, Apresentação e Introdução (capítulo 1), buscamos identificar uma visão mais geral sobre quem é o(a) estudante que esta política almeja produzir e, junto a isso, quem deve ser o(a) professor(a) para formar este(a) estudante. Já na terceira seção analisada, a área de Ciências da Natureza dos anos finais do Ensino Fundamental (capítulo 4 e, em especial, os subcapítulos 4.3, 4.3.1 e 4.3.1.2), objetivamos identificar como a disciplina ciências, neste nível de ensino, se articula na produção destes sujeitos.

Na primeira seção deste artigo buscamos identificar e analisar as teses culturais sobre como deveria ser o(a) professor(a) da educação básica. Na segunda seção, analisamos elementos gerais sobre quem o(a) professor(a) deveria formar, o(a) estudante da Educação Básica, àquele(a) almejado(a) pelo texto da política. Já na terceira seção, olhamos especificamente os itens - capítulo e subcapítulos - que tratavam da produção deste tipo específico de sujeito (o(a) estudante) no contexto da disciplina escolar de ciências dos anos finais do ensino fundamental. E provisoriamente concluímos tensionando sobre a maneira como nos tornamos professoras(es) no currículo de ciências. 


\section{Teses culturais sobre a docência: a produção de sujeitos(as) professores(as) na BNC-formação}

$\mathrm{Na}$ análise do Parecer CNE/CP n 22 de 2019, identificamos elementos para construir e apresentar, neste texto, duas teses culturais sobre a docência. São elas: a) as(os) professoras(es) como implementadores(as) da BNCC da Educação Básica; e b) as(os) professoras(es) responsáveis pela melhoria dos índices do país em avaliações de larga escala. Essas teses culturais são duas noções discursivamente montadas na BNC-Formação que entendemos participarem da produção de quem deveriam ser e como deveriam agir esses sujeitos professores(as) da política. Essas teses culturais igualmente delimitam quem os sujeitos professores(as) não deveriam ser e como não deveriam agir, produzindo classificações e categorizações que possibilitam o reconhecimento dos(as) 'bons' e 'maus' professores(as).

No documento, a BNCC é enunciada inaugurando "uma nova era da Educação Básica em nosso país” (Brasil, 2019, p. 1) e, para torná-la efetiva, os(as) professores(as) “devem desenvolver um conjunto de competências profissionais que os qualifiquem para colocar em prática as dez competências gerais, bem como as aprendizagens essenciais previstas na BNCC" (Brasil, 2019, p. 1). Percebemos aqui a construção de uma subjetividade docente que compreende as(os) professoras(es) como implementadores da BNCC da Educação Básica. Essa primeira tese cultural, identificada no texto da política, participa da produção de um sujeito que, ao ser formado a partir das competências profissionais da BNC-Formação (Brasil, 2019), torna-se apto a desenvolver a BNCC (Brasil, 2017) em sala de aula. Nesse mesmo movimento, a BNCC vai sendo construída como parte de uma política salvadora: como aquela pode oferecer uma formação integral ao estudante, pode auxiliar na superação da desigualdade educacional e assegurar uma educação de qualidade para todos (Brasil, 2019). É também nele que a subjetividade docente se aproxima cada vez mais da tarefa de desenvolver competências.

Rodrigues, Pereira e Mohr (2020), ao compararem as dez competências gerais presentes na BNCC com as dez competências gerais da BNC-Formação, percebem que elas, além de possuírem o mesmo número, enunciam conteúdos semelhantes. Para as autoras, isso demonstra o "alinhamento entre o que se espera que se aprenda pelos alunos na educação básica e o que se espera que os professores aprendam e ensinem" (Rodrigues, Pereira e Mohr, 2020, p. 27). Além disso, para formar docentes que desenvolvam essas competências gerais, a BNC-Formação aposta em uma formação inicial de professores(as) que aconteça a partir de três competências específicas, adjetivadas como profissionais, que "se integram e são interdependentes" (Brasil, 2019, p. 15): conhecimento profissional, prática profissional e engajamento profissional. Quanto à competência nomeada conhecimento profissional, esta

[...] pressupõe uma formação específica e permite a atuação docente autônoma. Retrata a aquisição de saberes que dão significado e sentido à prática profissional realizada em âmbito escolar. Os conhecimentos da área, da etapa e do componente curricular estão no âmago da competência. Os conteúdos curriculares são 
nucleares e imprescindíveis para a constituição de competências. Sem eles designados como recursos intelectuais, saberes ou conhecimentos - não há o que possa ser mobilizado pelo sujeito para agir assertivamente em uma dada situação (Brasil, 2019, p. 16).

Já a competência denominada prática profissional trata de "valorizar o conhecimento pedagógico do conteúdo, ou seja, a forma como esses são trabalhados em situações de sala" (Brasil, 2019, p. 16). Além disso, tal competência se associa a uma noção de prática docente que articula de forma contínua o objeto de conhecimento ao objeto de ensino, uma vez que:

A concomitância entre a aprendizagem dos objetos de conhecimento e a aprendizagem dos procedimentos e objetivos busca selecionar, ordenar, organizar e avaliar os objetos de ensino que fazem parte fundamental da formação e da relação permanente entre conhecimento e prática (Brasil, 2019, p. 16).

Thomas Popkewitz (2015) afirma que essa noção de prática, presente em reformas educacionais da formação de professoras(es) das últimas décadas, é uma abstração que expressa teorias sobre um(a) futuro(a) professor(a) cosmopolita ideal, que é capaz de atualizar-se por meio de pesquisas sobre sua própria prática e maximizar a utilidade do sistema escolar. Este tipo de pessoa, adjetivado como profissional, tem como tarefa gerenciar melhor as atividades pedagógicas para a produção de um ensino mais eficaz, o que se relaciona com a melhoria dos estudantes em avaliações (Popkewitz, 2015). De acordo com o autor, esses modelos de avaliação padronizados são codificados para medir e gerenciar o sistema escolar e participam da constituição de um sistema de pensamento que gera princípios que ordenam teorias, programas e avaliações, atualizando essa 'abstração' sobre a prática docente. Tais modelos visam, portanto, a modificar e controlar o mundo, através da criação de determinados tipos de pessoas (Popkewitz, 2015).

Por fim, a competência nomeada engajamento profissional é construída por meio da produção de um compromisso moral e ético do professor para com os demais sujeitos da educação: estudantes, gestores e toda a comunidade escolar (Brasil, 2019). Ela

[...] pressupõe o compromisso consigo mesmo (desenvolvimento pessoal e profissional), o compromisso com o outro (aprendizagem e pleno desenvolvimento do estudante) e o compromisso com os outros (interação com colegas, atores educacionais, comunidade e sociedade) (Brasil, 2019, p. 17).

Outra grande preocupação indicada no texto da política analisada em questão (BNCFormação, 2019), em meio à qual entendemos a segunda tese cultural deste artigo, se refere ao fato de que as(os) professoras(es) devem se responsabilizar pelo melhoramento dos índices do país nas avaliações de larga escala. A BNC-Formação se constitui como parte de uma política ancorada em dados das avaliações nacionais brasileiras - como os resultados da Avaliação Nacional de Alfabetização (ANA) de 2016 e do Sistema de Avaliação da Educação Básica (Saeb) entre os anos de 2007 e 2015 -, a fim de guiar uma 'melhor' política nacional 
de formação de professores(as). Tal política se justifica, portanto, pela via dos índices baixos e inesperados de aprendizagem. Sobre isso a BNC-Formação reafirma que:

Esses resultados nos levam a pensar em dois aspectos. $\mathrm{O}$ primeiro se refere à regulação da formação e do exercício profissional para o magistério, conforme o inciso III do art. 13 da LDB, pelo qual os docentes devem se incumbir de zelar pela aprendizagem dos estudantes. [...] Nesse sentido, a aprendizagem passa a ser a principal incumbência do professor, ou seja, a centralidade do tradicional processo de ensino e de aprendizagem não está mais na atividade meio, ou no simples repasse de informações, mas na atividade fim, que diz respeito ao zelo pela aprendizagem dos estudantes, uma vez que a finalidade primordial das atividades de ensino está nos resultados de aprendizagem. (Brasil, 2019, p.05)

O documento expõe os 'fundamentos' de tal política tanto a partir de influências nacionais quanto internacionais. O contexto de influência, noção mobilizada por Richard Bowe, Stephen Ball e Anne Gold (1992), trata-se do fenômeno de construção dos discursos e da disputa pela influência e definição ideológica das políticas, o que pode ser exemplificado pelos canais oficiais do governo, dos partidos e do legislativo. Nele, a ideia é legitimar os discursos para basear as políticas. A BNC-Formação estipula as influências do contexto internacional como parâmetro para demarcar uma 'necessidade' de qualificar os(as) professores(as) para um melhor resultado do processo de aprendizagem dos estudantes. Afinal,

Conforme os vários estudos têm apontado, entre eles o da Organização para a Cooperação e Desenvolvimento Econômico (OCDE), que envolve o levantamento das políticas relativas aos professores da Educação Básica em 25 países membros, constatou-se que a qualificação dos professores para a qualidade do ensino ministrado é o fator mais importante para explicar o desempenho dos estudantes. Daí porque a formação docente é, dentre os diversos fatores que contribuem para a melhoria da qualidade do ensino e da aprendizagem escolar, o que deve ganhar maior atenção das políticas públicas para a área." (Brasil, 2019, p. 5, grifo nosso)

Assim reconhecemos com Mainardes (2006) que há um certo tipo de interação dialética na produção da política, tendo em vista os contextos globais e locais, e levando em consideração que esse processo de produção "não é uma mera transposição e transferência, pois as políticas são recontextualizadas dentro de contextos nacionais específicos" (2006, p. 52). É em meio a tal processo que o texto da política assume uma busca pela qualidade do ensino e da aprendizagem escolar que é constantemente atrelada a uma formação docente 'adequada', que visa a aprimorar habilidades e competências dos(as) professores(as), baseada nos resultados das avaliações nacionais e estudos internacionais. Esses resultados emergem como instrumentos que significam as políticas, um termômetro de qualidade da educação no país. Entendemos que a noção de qualidade nesse contexto "veio se associando a padrões e 
normas de desempenho que acabam por produzir quem devemos ser e o que devemos saber, nas posições de sujeito de professores e de estudantes da educação básica" (Santos; Ferreira, 2020, p. 27). Para a obtenção de tal qualidade no ensino, a BNC-Formação (2019) enuncia uma série de problemas a serem enfrentamos na formação do professor brasileiro. São eles:

(a) professores em situação de improviso, ou seja, formados em várias outras áreas do conhecimento, por falta de licenciados na disciplina, ou licenciandos em curso; (b) ausência de uma política nacional específica e articulada, dirigida para a melhor qualificação da formação inicial de professores, em qualquer modalidade; (c) pouca disseminação e adoção das orientações e resultados de discussões e pesquisas sobre formação de professores na institucionalização dos cursos formadores nas diferentes áreas disciplinares abrangidas; (d) diretrizes curriculares nacionais dos cursos de licenciatura com forte tradição no aspecto disciplinar, com vaga referência à formação de professores, e muitas vezes tratando praticamente apenas dos bacharelados; (e) estruturas curriculares fragmentadas, sem disciplinas articuladoras, com ementas genéricas quanto aos saberes pedagógicos, e com visível abreviação da formação; (f) estágios curriculares sem projetos e apoios institucionais, com acompanhamento e avaliação precários; $(\mathrm{g}$ ) conversão em ritmo acelerado da oferta de cursos presenciais em cursos a distância, e o excesso de instituições que oferecem esses cursos nessa modalidade; (h) pouco preparo de docentes das Instituições de Ensino Superior (IES) para atuar na formação de professores; (i) características socioeducacionais e culturais dos estudantes dos cursos de licenciatura, que merecem ser consideradas para melhor formação e permanência dos discentes no curso" (Brasil, 2019, p. 5-6, grifos nossos)

Destacamos aqui um dos aspectos que chama a atenção nesse movimento de apontar as fragilidades que levaram o professor da educação básica a ser 'mal' formado e responsável, portanto, pela baixa qualidade da educação. A desarticulação dos currículos nos cursos de formação de professores(as) é enunciada, por exemplo, como efeito da ausência de uma política nacional específica e articulada, o que se associa as noções de comum e de nacional por meio da qual se objetiva a implementação de ideias homogêneas de como deveríamos formar professoras(es) e estudantes (Macedo, 2014; 2015). Para Santos e Ferreira (2020, p. 34), pelo menos desde os anos de 1980 veio se constituindo um sistema de pensamento "que, simultaneamente, obedece e determina regras que nos informam modos de pensar a qualidade associada ao estabelecimento de referenciais curriculares que permitem (...) comparações e distinções".

Associado a esse aspecto, a BNC-Formação (2019) enuncia o improviso, assim como a ignorância acerca das características dos estudantes e dos resultados de pesquisa como obstáculos à melhoria da qualidade da educação básica. Nesse cenário, a formação de professores(as) deveria contar com docentes e currículos 'adequados', de modo a combater esse conjunto de problemas e fazer com que os(as) professores(as) assumam o protagonismo como implementadores(as) da BNCC da Educação Básica e, consequentemente, pela 
melhoria dos índices avaliativos do país em avaliações de larga escala.

\section{Quem deveríamos formar para atuar na (e com a) BNCC?}

Nesta pesquisa, assumimos que para compreender as formas pelas quais o professor é subjetivado pelo currículo, faz-se necessário nos debruçar sobre quem a política almeja que o professor ensine. Afinal, assumimos que esses dois sujeitos - o professor e o estudante participam de um processo relacional por meio do qual tornar-se professor está diretamente relacionado a um modo de ser do estudante. Identificamos, assim, elementos na BNCC (Brasil, 2017) que nos possibilitaram refletir acerca de quem o(a) estudante da Educação Básica deveria ser (Popkewitz, 2020): aquele(a) que é almejado, mas também produzido por esta política educacional. $\mathrm{O}$ primeiro elemento trata da formação de um(a) estudante preparado para o futuro, capacitado(a) a desenvolver as competências gerais da BNCC. É possível perceber na política uma noção de base nacional e comum como "um documento completo e contemporâneo, que corresponde às demandas do estudante desta época, preparando-o para o futuro" (Brasil, 2017, p. 5). A partir dessa base, objetiva-se formar um(a) estudante que, por ter garantido aprendizagens essenciais e desenvolvido integralmente as dez competências gerais presentes no documento, sente-se preparado para realizar "as escolhas necessárias para concretização dos seus projetos de vida e a continuidade dos estudos" (Brasil, 2017, p. 5).

$\mathrm{O}$ segundo elemento trata de um(a) estudante que, a partir de uma aprendizagem contínua, torna-se autossuficiente e capaz de tomar as melhores decisões para si e para os outros. É possível perceber esse discurso sendo produzido e disseminado nas dez "Competências Gerais da Educação Básica" presentes na BNCC:

Valorizar e utilizar os conhecimentos historicamente construídos sobre o mundo físico, social, cultural e digital para entender e explicar a realidade, continuar aprendendo e colaborar para a construção de uma sociedade justa, democrática e inclusiva.

Exercitar a curiosidade intelectual e recorrer à abordagem própria das ciências, incluindo a investigação, a reflexão, a análise crítica, a imaginação e a criatividade, para investigar causas, elaborar e testar hipóteses, formular e resolver problemas e criar soluções (inclusive tecnológicas) com base nos conhecimentos das diferentes áreas.

Valorizar e fruir as diversas manifestações artísticas e culturais, das locais às mundiais, e também participar de práticas diversificadas da produção artísticocultural.

Utilizar diferentes linguagens - verbal (oral ou visual-motora, como Libras, e escrita), corporal, visual, sonora e digital -, bem como conhecimentos das linguagens artística, matemática e científica, para se expressar e partilhar informações, experiências, ideias e sentimentos em diferentes contextos e produzir sentidos que levem ao entendimento mútuo. 
Compreender, utilizar e criar tecnologias digitais de informação e comunicação de forma crítica, significativa, reflexiva e ética nas diversas práticas sociais (incluindo as escolares) para se comunicar, acessar e disseminar informações, produzir conhecimentos, resolver problemas e exercer protagonismo e autoria na vida pessoal e coletiva.

Valorizar a diversidade de saberes e vivências culturais e apropriar-se de conhecimentos e experiências que lhe possibilitem entender as relações próprias do mundo do trabalho e fazer escolhas alinhadas ao exercício da cidadania e ao seu projeto de vida, com liberdade, autonomia, consciência crítica e responsabilidade.

Argumentar com base em fatos, dados e informações confiáveis para formular, negociar e defender ideias, pontos de vista e decisões comuns que respeitem e promovam os direitos humanos, a consciência socioambiental e o consumo responsável em âmbito local, regional e global, com posicionamento ético em relação ao cuidado de si mesmo, dos outros e do planeta.

Conhecer-se, apreciar-se e cuidar de sua saúde física e emocional, compreendendo-se na diversidade humana e reconhecendo suas emoções e as dos outros, com autocrítica e capacidade para lidar com elas.

Exercitar a empatia, o diálogo, a resolução de conflitos e a cooperação, fazendo-se respeitar e promovendo o respeito ao outro e aos direitos humanos, com acolhimento e valorização da diversidade de indivíduos e de grupos sociais, seus saberes, identidades, culturas e potencialidades, sem preconceitos de qualquer natureza.

Agir pessoal e coletivamente com autonomia, responsabilidade, flexibilidade, resiliência e determinação, tomando decisões com base em princípios éticos, democráticos, inclusivos, sustentáveis e solidários. (Brasil, 2017, p. 9 - 10, grifos nossos).

Esta aprendizagem contínua e autossuficiente, almejada pela BNCC, está relacionada a um processo de aprender a aprender e de aprender a aplicar esse conhecimento no dia a dia. Isso significa, de acordo com o texto legal, a produção do seguinte tipo de estudante:

No novo cenário mundial, reconhecer-se em seu contexto histórico e cultural, comunicar-se, ser criativo, analítico-crítico, participativo, aberto ao novo, colaborativo, resiliente, produtivo e responsável requer muito mais do que o acúmulo de informações. Requer o desenvolvimento de competências para aprender a aprender, saber lidar com a informação cada vez mais disponível, atuar com discernimento e responsabilidade nos contextos das culturas digitais, aplicar conhecimentos para resolver problemas, ter autonomia para tomar decisões, ser proativo para identificar os dados de uma situação e buscar soluções, conviver e aprender com as diferenças e as diversidades (Brasil, 2017, p. 14, grifos nossos).

Tais competências gerais da BNCC vão operando como ferramentas discursivas para a produção deste tipo específico de estudante na escola. É nesse mesmo cenário que a docência 
vai sendo enunciada como responsável pelo desenvolvimento dessas ferramentas, uma vez que "as decisões pedagógicas [dos professores] devem estar orientadas para o desenvolvimento de competências" que privilegiem o 'saber' e o 'saber fazer' (Brasil, 2017, p. 13). Afinal,

Por meio da indicação clara do que os alunos devem "saber" (considerando a constituição de conhecimentos, habilidades, atitudes e valores) e, sobretudo, do que devem "saber fazer" (considerando a mobilização desses conhecimentos, habilidades, atitudes e valores para resolver demandas complexas da vida cotidiana, do pleno exercício da cidadania e do mundo do trabalho), a explicitação das competências oferece referências para o fortalecimento de ações que assegurem as aprendizagens essenciais definidas na BNCC." (Brasil, 2017, p. 13, grifo nosso)

Nesse movimento, "as aprendizagens essenciais definidas na BNCC” vão sendo construídas tanto como direitos quanto como deveres dos estudantes, visto que estes sujeitos serão mensurados e classificados posteriormente via avaliações de larga escala. Essa política situa os(as) estudantes em um movimento de duplo gesto (Popkewitz, 2011); afinal, eles são incluídos(as) a partir da constituição dos critérios que visam a garantir as aprendizagens essenciais a todos e todas, mas essa garantia é também produtora das fronteiras e limites a partir dos quais vão ser abjetados(as) os(as) estudantes que não atingirem os índices esperados.

\section{Como formar para a disciplina escolar Ciências?}

A partir das teses culturais discutidas nas seções anteriores, com efeitos na constituição dos estudantes da educação básica, analisamos a especificidade da disciplina escolar Ciências nos anos finais do ensino fundamental nesse processo. Assim, ao analisar o texto da BNCC voltado para as Ciências da Natureza, identificamos o modo como esse componente curricular participa da constituição do estudante desse nível de ensino como um sujeito preparado(a) para o futuro, capacitado(a) a tomar as melhores decisões para si e para os outros. No documento, o(a) estudante da disciplina escolar Ciências é enunciado como aquele(a) capaz de compreender, interpretar e transformar ao mundo e a si mesmo tomando como referência os conhecimentos e procedimentos das Ciências da Natureza. Para realizar essa tarefa, o professor deve atuar no "desenvolvimento do letramento científico", uma vez que aprender ciência não é a finalidade última do letramento, mas, sim, o desenvolvimento da capacidade de atuação no e sobre o mundo, importante ao exercício pleno da cidadania (Brasil, 2017, p. 321, grifos nossos). Tal atuação deve ler em conta a seguintes competências específicas, entre outras:

[...] (2) Compreender conceitos fundamentais e estruturas explicativas das Ciências da Natureza, bem como dominar processos, práticas e 
procedimentos da investigação científica, de modo a sentir segurança no debate de questões científicas, tecnológicas, socioambientais e do mundo do trabalho, continuar aprendendo e colaborar para a construção de uma sociedade justa, democrática e inclusiva. [...]

(5) Construir argumentos com base em dados, evidências e informações confiáveis e negociar e defender ideias e pontos de vista que promovam a consciência socioambiental e o respeito a si próprio e ao outro, acolhendo e valorizando a diversidade de indivíduos e de grupos sociais, sem preconceitos de qualquer natureza. [...]

(8) Agir pessoal e coletivamente com respeito, autonomia, responsabilidade, flexibilidade, resiliência e determinação, recorrendo aos conhecimentos das Ciências da Natureza para tomar decisões frente a questões científicotecnológicas e socioambientais e a respeito da saúde individual e coletiva, com base em princípios éticos, democráticos, sustentáveis e solidários. (Brasil, 2017, p. 324, grifos nossos)

Para o desenvolvimento dessas competências, o professor da disciplina escolar deve participar da produção de um currículo que seleciona e organiza conhecimentos em três unidades que se repetem ao longo de todo o ensino fundamental. São eles: matéria e energia; vida e evolução; Terra e universo. Nos anos finais, a temática matéria e energia almeja, por exemplo, a formação de um(a) estudante que saiba produzir e avaliar tecnologias que visam o aproveitamento sustentável de recursos naturais. Nesse movimento, a intenção é a seguinte:

[...] fundamentar-se no conhecimento científico para, por exemplo, avaliar vantagens e desvantagens da produção de produtos sintéticos a partir de recursos naturais, da produção e do uso de determinados combustíveis, bem como da produção, da transformação e da propagação de diferentes tipos de energia e do funcionamento de artefatos e equipamentos que possibilitam novas formas de interação com o ambiente, estimulando tanto a reflexão para hábitos mais sustentáveis no uso dos recursos naturais e científico-tecnológicos quanto a produção de novas tecnologias e o desenvolvimento de ações coletivas de aproveitamento responsável dos recursos (Brasil, 2017, p. 326).

De igual modo, a temática vida e evolução também tem como foco o desenvolvimento de um(a) estudante que saiba utilizar os recursos naturais de maneira sustentável:

Nos anos finais, a partir do reconhecimento das relações que ocorrem na natureza, evidencia-se a participação do ser humano nas cadeias alimentares e como elemento modificador do ambiente, seja evidenciando maneiras mais eficientes de usar os recursos naturais sem desperdícios, seja discutindo as implicações do consumo excessivo e descarte inadequado dos resíduos. Contempla-se, também, o incentivo à proposição e adoção de alternativas individuais e coletivas, ancoradas na aplicação do conhecimento científico, que concorram para a sustentabilidade socioambiental. Assim, busca-se promover e incentivar uma convivência em maior sintonia com o ambiente, por meio do uso inteligente e 
responsável dos recursos naturais, para que estes se recomponham no presente e se mantenham no futuro (Brasil, 2017, p. 326-327).

Esta segunda temática também pretende que os(as) estudantes assumam o protagonismo no que se refere ao autocuidado com o seu próprio corpo e com o corpo do outro, além de compreenderem qual o papel do Estado e das políticas públicas para o desenvolvimento de condições propícias à saúde (Brasil, 2017). Por fỉm, a temática Terra e universo objetiva a formação de um(a) estudante que saiba "lançar mão do conhecimento científico e tecnológico para compreender os fenômenos e conhecer o mundo, o ambiente, a dinâmica da natureza" (Brasil, 2017, p. 342). Almeja-se que estes sujeitos, a partir de suas vivências, saberes e curiosidades sobre o mundo natural e material, obtenham uma formação científica capaz de "explorar aspectos mais complexos das relações consigo mesmos, com os outros, com a natureza, com as tecnologias e com o ambiente; ter consciência dos valores éticos e políticos envolvidos nessas relações" (Brasil, 2017, p. 342).

Nesse currículo para a disciplina escolar Ciências, com vistas ao desenvolvimento das competências já anteriormente referidas, a BNCC também almeja que o(a) estudante aprenda a compreender, interpretar e transformar o mundo e a si mesmo com base nos procedimentos e métodos das ciências. Tais procedimentos e métodos são construídos ao longo da política como o desenvolvimento de etapas de um processo investigativo: definição de problemas; levantamento, análise e representação; comunicação; intervenção (Brasil, 2017). De acordo com o texto legal, esse processo investigativo "deve ser entendido como elemento central na formação dos estudantes" e seu desenvolvimento "deve ser atrelado a situações didáticas planejadas ao longo de toda a educação básica” (Brasil, 2017, p. 322). É em meio a tal movimento, no qual se ensinam conhecimentos, procedimentos e métodos, que as(os) professoras(es) da disciplina escolar Ciências são continuamente formados na (e para a) docência.

\section{Efeitos na formação de professores para as ciências: considerações provisórias sobre o tornar-se}

Inicialmente faz-se necessário reconhecer que a ideia de um consenso comum nas políticas curriculares educacionais "tem relação com um projeto econômico global, capaz de produzir discursos que se capilarizam socialmente" (Lopes \& Macedo, 2011, p. 253). É nesse sentido que compreendemos as influências globais de um modo de vida cosmopolita para a produção dos currículos no cenário brasileiro. O ideal do cosmopolitismo é, segundo Thomas Popkewitz (2020), a formação de um cidadão autorrealizado e autossuficiente, um sujeito da razão. Para realizar essa tarefa, "o cosmopolitismo deveria criar uma unidade por meio da atribuição universal de princípios de razão e ciência que resultaria em uma humanidade progressista e inclusiva" (Popkewitz, 2020, p. 52). É nesse contexto que, ao longo de nossa pesquisa, foi possível identificar duas teses culturais sobre a subjetividade docente que, articuladas, produzem a formação de professores(as) nas políticas curriculares recentes no 
país: i) professoras(es) como implementadores da BNCC da Educação Básica; e ii) professoras(es) responsáveis pela melhoria dos índices do país em avaliações de larga escala.

Em tal contexto, a formação dos(as) professores(as) que atuam nas disciplinas escolares em ciências vai sendo produzida de modo a colocar os conhecimentos, procedimentos e métodos das ciências de referência - em especial as Ciências Biológicas, a Física e a Química - e a utilidade social da disciplina a serviço dessas teses culturais, em um movimento no qual a igualdade, a qualidade e a equidade serão produzidas por um professor cientificamente competente. Afinal, esse profissional deverá ser capaz, por exemplo, de fazer com que seus estudantes do ensino fundamental passem a agir com autonomia e responsabilidade, recorrendo aos conhecimentos, procedimentos e métodos dessas ciências "para tomar decisões frente a questões científico-tecnológicas e socioambientais" (Brasil, 2017, p. 324), no que se diz respeito às questões de saúde individual e coletiva. Como indicado anteriormente, ao longo da análise, o professor deve objetivar um processo de ensino aprendizagem do qual resulte o perfil de um(a) estudante solucionador de problemas. Sobre essa questão, concordamos com Thomas Popkewitz (2020, p. 51) quando o autor destaca que:

Desenvolver currículos e realizar pesquisas sobre a resolução de problemas é teorizar, regularizar e racionalizar processos para mudar pessoas. A inserção de teorias sobre resolução de problemas no currículo é um dispositivo de inscrição para ordenar e classificar a conduta. As teses culturais do solucionador de problemas não são apenas sobre o que uma criança é. Elas também são práticas para governar o que uma criança deverá vir a ser.

Mas incitar a formação de um sujeito da razão não se refere apenas ao processo de formação do estudante. Ele se refere, também, ao professor como o responsável por implementar a BNCC de modo a ser capaz de gerenciar racionalmente as aprendizagens. Em tal movimento, ancorado nas teses culturais já explicitadas, os(as) professores(as) das disciplinas escolares em ciências vão se responsabilizando pelo desenvolvimento de competências, neles e nos estudantes, capazes de promover e assegurar a igualdade e a qualidade da educação. Para realizar essa tarefa, os(as) estudantes devem se constituir como sujeitos da diversidade, aprendendo com a ciência a respeitar o outro. Afinal, é através do conhecimento das ciências da natureza que os(as) estudantes serão capazes de serem

[...] protagonistas na escolha de posicionamentos que valorizem as experiências pessoais e coletivas, e representem o autocuidado com seu corpo e o respeito com o do outro, na perspectiva do cuidado integral à saúde física, mental, sexual e reprodutiva (Brasil, 2017, p. 343).

Em tal movimento, como já explicitado, ao criar categorizações e classificações que produzem tais estudantes, estamos produzindo, simultaneamente, o espaço discursivo do estudante 'abjetado', aquele que será 'deixado para trás' no processo educativo, uma vez que: 
O reconhecimento de populações específicas para inclusão é uma resposta aos compromissos para se corrigir injustiças; no entanto, o próprio desejo de incluir está inserido nos sistemas de pensamento que criaram um continuum de valores que diferenciam, dividem e abjetam. Isso é evidente ao se estudar as reformas de currículo e de formação de professores e as pesquisas centradas no problema da equidade. O tema da salvação, referente a "todas as crianças podem aprender", é um dos que sustenta a "sociedade justa", que ironicamente implica narrativas e imagens quase totalmente focalizadas no tipo de criança que não pertence ao espaço de "todas as crianças". (Popkewitz, 2020, p. 53, grifos do autor)

Na tentativa de produzir outras leituras dos textos das políticas, em Richard Bowe, Stephen Ball e Anne Gold (1992) encontramos instigantes possibilidades de percebê-los sendo reconfigurados também no contexto da prática. É nesse momento que percebemos que, para além do teor mandatório de um currículo nacional, ele atua na constituição das subjetividades docentes, demandando um certo tipo de professor, capaz de colocá-lo em prática. Seríamos então capazes de fugir das normas impostas pelas políticas curriculares nacionais? Há possibilidade de tornar-se professor fora das normatividades educacionais? Judith Butler (2019) teoriza sobre as possibilidades de agirmos no constante processo de nos tornarmos sujeitos. É decerto que somos subordinados pelo poder da normatividade, ela faz parte do que nos constitui como sujeitos(as)-professore(as)s. Mas há a possibilidade de agir, no sentido de fazer da normatividade uma outra coisa, o que não deve ser confundido como sair da norma (como se assim pudéssemos fazer).

Neste cenário, nas palavras de Carmen Teresa Gabriel e Natália Rodrigues Mendes (2019, p. 724, grifos nossos), focalizar as trajetórias de professores(as) e estudantes "nos oferece possibilidades de abrir caminhos para deixar vazar a criatividade dos modos de vida que compõem o universo curricular e não se esgotam na normatividade, mas apontam para as diferentes formas de habitar a norma". Isso significa assumir uma noção de poder produtivo, do qual não se 'escapa', uma vez que:

(...) assumir o poder não consiste na fácil tarefa de retirá-lo de um lugar, transferilo intacto e imediatamente se apropriar dele; o ato de apropriação pode envolver uma alteração do poder, de modo que o poder assumido ou apropriado atue contra o poder que lhe possibilitou ser assumido (Butler, 2019, p. 21).

Assim, ainda que imersos nas políticas recentes, reconhecemos formas de luta que se dão em meio às relações de poder, produzindo outras demandas e futuros possíveis. Em tal movimento, assumimos outras formas de agir de professores(as) e estudantes na ressignificação dos modos como a política pretende moldá-los. Sílvio Galo (2002) delimita dois tipos de educação: a maior, que se refere às políticas curriculares nacionais; a menor, que diz respeito aos atos de "resistência e revolta" dos sujeitos da educação (professores(as) e estudantes). Para o autor, "se a educação maior é produzida na macropolítica, nos gabinetes, expressa nos documentos, a educação menor está no âmbito da micropolítica, na sala de aula, 
expressa nas ações cotidianas de cada um" (Galo, 2002, p. 173). Percebemos, então, que se na luta política é imprescindível agirmos nas instâncias maiores, é também irremediável tornar visível as formas por meio das quais os sujeitos(as)-professores(as) habitam a norma. É nesse ponto que se localiza a resistência, nada mais que uma forma de recuperação do poder que nos permite constantemente nos tornar através da reflexividade (Butler, 2019). É nele, portanto, que encontramos brechas para desterritorializar os processos educativos, podendo assim encontrar outras formas de fazer educação que questionam e subvertem a normatividade.

\section{Notas:}

1. Estamos nos referindo ao conjunto de disciplinas escolares que, na educação básica, se encarregam de ensinar os conhecimentos das ciências físicas e naturais. São elas: Biologia, Ciências, Física e Química.

2. Este projeto de resolução, apresentado pelo parecer, torna-se posteriormente a Resolução $\mathrm{CNE} / \mathrm{CP} \mathrm{n}^{\circ} 2$, de 20 de dezembro de 2019, publicado no Diário Oficial da União em 15 de abril de 2020.

\section{Referências}

BRASIL. Base Nacional Comum Curricular. Brasília: Ministério da Educação, 2017. Disponível em:< http://portal.mec.gov.br/index.php?option=com_docman\&view=download\&alias=79601 -anexo-textobncc-reexportado-pdf-2\&category_slug=dezembro-2017-pdf\&Itemid=30192>. Acesso em: 14 ago. 2021.

BRASIL. Ministério da Educação. Conselho Nacional de Educação. Parecer CNE/GP 22 de 07 de novembro de 2019, publicado em 20 de dezembro de 2019. Diretrizes Curriculares Nacionais para a Formação Inicial de Professores para a Educação Básica e a Base Nacional Comum para Formação Inicial de Professores da Educação Básica (BNC - Formação). 2019a. Disponível em: $<$ http://portal.mec.gov.br/cne/arquivos/pdf/022.pdf> Acesso em: 19 ago. 2021.

BOWE, R.; BALL, S.; GOLD, A. Reforming education \& changing schools: case studies in policy sociology. London: Routledge, 1992.

BUTLER, Judith. A vida psíquica do poder. Teorias da sujeição. Belo Horizonte: Autêntica, 2019.

BUTLER, Judith. O que é a crítica? um ensaio sobre a virtude de Foucault. Trad. Gustavo Hessmann Dalaqua. Cadernos De Ética E Filosofia Política, 1(22), 159-179. 2013. Disponível em: https://www.revistas.usp.br/cefp/article/view/59447/62615. Acesso em: 04 ago. 2021.

BUTLER, Judith. Problemas de Gênero: feminismo e subversão da identidade. $19^{\mathrm{a}}$ ed. Rio de Janeiro: Civilização Brasileira, 2020.

FERREIRA, M. S. Currículo e cultura: diálogos com as disciplinas escolares Ciências e Biologia. In: Antonio Flavio Moreira; Vera Maria Candau. (Org.). Currículos, disciplinas escolares e culturas. 1ed. Petrópolis: Vozes, 2014, p. 185-213.

FERREIRA, Marcia Serra. História do currículo e das disciplinas: produzindo uma abordagem discursiva para investigar a formação inicial de professores nas Ciências Biológicas. In: LEITE, Miriam; GABRIEL, C. T. Linguagem, Discurso, Pesquisa e Educação. Rio de Janeiro: FAPERJ, 2015.

FERREIRA, Marcia Serra; SANTOS, André Vitor Fernandes. Discursos curriculares no/do te: subsídios para uma articulação entre a história e as políticas de currículo. In: LOPES, Alice Casemiro; OLIVEIRA, Maria Betânia. Políticas de currículo: pesquisas e articulações discursivas. Editora CRV, 2017. 
FOUCAULT, Michel. Arqueologia do Saber. Rio de Janeiro: Forense Universitária, 2008.

GABRIEL, Carmen Teresa; MENDES, Natália Rodrigues. A interface sujeito-agência no campo curricular: que contribuições das pesquisas (auto)biográficas? Revista Brasileira de Pesquisa (Auto)Biográfica, Salvador, v. $04, \quad$ n. 11, p. 714-728, maio/ago. 2019. Disponível em: <https://www.revistas.uneb.br/index.php/rbpab/article/view/5948/pdf>. Acesso em: 20 ago. 2021.

GALLO, Silvio. Em torno de uma Educação Menor. Educação \& Realidade. p. 169-178 jul./dez. 2002. Disponível em: < https://seer.ufrgs.br/educacaoerealidade/article/view/25926/15194>. Acesso em: 02 ago. 2021.

LOPES, Alice Casimiro; MACEDO, Elizabeth. Contribuições de Stephen Ball para o estudo de políticas de currículo. In: BALL, Stephen J.; MAINARDES, J (org.). Políticas educacionais: questões e dilemas. São Paulo: Cortez, 2011.

MACEDO, Elizabeth. Base Nacional Comum para currículos: direitos de aprendizagem e desenvolvimento para quem? Educ. Soc., Campinas, v. 36, nº. 133, p. 891-908, out.-dez., 2015. Disponível em: <https://www.scielo.br/j/es/a/MxBmvSrkFgnFRrm5XsRWzgg/?format=pdf\&lang=pt>. Acesso em: 15 jul. 2021.

MACEDO, Elizabeth. Base Nacional Curricular Comum novas formas de sociabilidade produzindo sentidos para educação. Revista e Curriculum, São Paulo, v.12, n. 03 p.1530-1555. out./dez. 2014. Disponível: $<$ https://revistas.pucsp.br/index.php/curriculum/article/view/21666/15916>. Acesso em: 10 jul. 2021.

MAINARDES, Jefferson. Abordagem do ciclo de políticas: uma contribuição para a análise de políticas educacionais. In: Educ. Soc., Campinas, vol. 27, n. 94, p. 47-69, jan./abr. 2006. Disponível em:< https://www.scielo.br/j/es/a/NGFTXWNtTvxYtCQHCJFyhsJ/?format=pdf\&lang=pt>. Acesso em: 30 ago. 2021.

MAINARDES, Jefferson; FERREIRA, Márcia, Santos; TELLO, César. Análise de políticas: fundamentos e principais debates teórico-metodológicos. In: BALL, Stephen J.; MAINARDES, J (org.). Políticas educacionais: questões e dilemas. São Paulo: Cortez, 2011.

POPKEWITZ, Thomas. S. Estudos curriculares, história do currículo e teoria curricular: a razão da razão. Revista Em Aberto, v. 33, n. 107, p. 47-68, 2020. Disponível em:< http://emaberto.inep.gov.br/ojs3/index.php/emaberto/article/view/4555/3775>. Acesso em 23 ago. 2021.

POPKEWITZ, Thomas. S. La práctica como teoria del cambio. Investigación sobre professores y su formación. Profesorado. Revista de Curriculum y Formación de Profesorado, v. 19, n. 3, set-dez, 428 - 453, 2015. Disponível em: < https://www.redalyc.org/pdf/567/56743410015.pdf>. Acesso em: 13 jul. 2021.

POPKEWITZ, Thomas S. Cosmopolitismo, o cidadão e os processos de abjeção: os duplos gestos da pedagogia. Cadernos de Educação, 38, $361 \quad-\quad 391, \quad 2011 . \quad$ Disponível em:< https://periodicos.ufpel.edu.br/ojs2/index.php/caduc/article/view/1575/1461>. Acesso em: 05 ago. 2021.

RODRIGUES, Larissa Zancan; PEREIRA, Beatriz; MOHR, Adriana. O documento "Proposta para Base Nacional Comum para Formação de Professores da Educação Básica" (BNCFP): Dez razões para temer e contestar a BNCFP. Revista Brasileira de Pesquisa em Educação em Ciências, v. 20, p. 1 - 39, 2020. Disponível em: < https://periodicos.ufmg.br/index.php/rbpec/article/view/16205/15250>. Acesso em: 05 ago. 2021.

SANTOS, André Vitor Fernandes; FERREIRA, Marcia Serra. Currículo nacional comum: uma questão de qualidade? Revista Em Aberto, v. 33, n. 107, p. 27-46, 2020. Disponível em:< http://www.emaberto.inep.gov.br/ojs3/index.php/emaberto/article/view/4554>. Acesso em: 05 ago. 2021. 


\section{Correspondência}

Catarina de Cássia Moreira: Doutoranda em Educação no Programa de Pós-Graduação em Educação (PPGE) da Universidade Federal do Rio de Janeiro (UFRJ). É pesquisadora do Grupo de Estudos em História do Currículo, da mesma universidade.

E-mail: catherine.cassia@gmail.com

Beatriz Pereira: Doutoranda em Educação Científica e Tecnológica no Programa de Pós-Graduação em Educação Científica e Tecnológica (PPGECT) da Universidade Federal de Santa Catarina (UFSC). Realiza pesquisas junto ao grupo Casulo: Pesquisa e Educação em Ciências e Biologia da UFSC e ao Grupo de Estudos em História do Currículo da UFRJ.

E-mail: beatrizsofka@gmail.com

Marcia Serra Ferreira: Professora da Universidade Federal do Rio de Janeiro, atuando na Faculdade de Educação, no Programa de Pós-Graduação em Educação (PPGE) e no Mestrado Profissional em Ensino de Biologia em Rede Nacional (ProfBio). É bolsista de produtividade 1D do CNPq e Cientista do Nosso Estado (CNE/Faperj). Coordena o Grupo de Estudos em História do Currículo.

E-mail: marciaserraferreira@ gmail.com

Texto publicado em Currículo sem Fronteiras com autorização dos autores. 